\title{
Clinically significant drug-drug interactions involving opioid analgesics used for pain treatment in patients with cancer: a systematic review
}

This article was published in the following Dove Press journal:

Drug Design, Development and Therapy

16 September 2015

Number of times this article has been viewed

\author{
Aleksandra Kotlinska- \\ Lemieszek' \\ Pål Klepstad ${ }^{2,3,6}$ \\ Dagny Faksvåg Haugen ${ }^{2,4,5}$ \\ 'Palliative Medicine Chair and \\ Department, University Hospital \\ of the Lord's Transfiguration, Karol \\ Marcinkowski University of Medical \\ Sciences, Poznan, Poland; ${ }^{2}$ European \\ Palliative Care Research Centre, Faculty \\ of Medicine, Norwegian University of \\ Science and Technology,Trondheim, \\ Norway; ${ }^{3}$ Department of \\ Anaesthesiology and Intensive Care \\ Medicine, St Olavs Hospital, Trondheim, \\ Norway; ${ }^{4}$ Regional Centre of Excellence \\ for Palliative Care, Haukeland \\ University Hospital, Bergen, Norway; \\ ${ }^{5}$ Department of Clinical Medicine KI, \\ University of Bergen, Bergen, Norway; \\ ${ }^{6}$ Department of Circulation and \\ Medical Imaging, Norwegian University \\ of Science and Technology, Trondheim, \\ Norway
}

Background: Opioids are the most frequently used drugs to treat pain in cancer patients. In some patients, however, opioids can cause adverse effects and drug-drug interactions. No advice concerning the combination of opioids and other drugs is given in the current European guidelines.

Objective: To identify studies that report clinically significant drug-drug interactions involving opioids used for pain treatment in adult cancer patients.

Design and data sources: Systematic review with searches in Embase, MEDLINE, and Cochrane Central Register of Controlled Trials from the start of the databases (Embase from 1980) through January 2014. In addition, reference lists of relevant full-text papers were handsearched.

Results: Of 901 retrieved papers, 112 were considered as potentially eligible. After full-text reading, 17 were included in the final analysis, together with 15 papers identified through handsearching of reference lists. All of the 32 included publications were case reports or case series. Clinical manifestations of drug-drug interactions involving opioids were grouped as follows: 1) sedation and respiratory depression, 2) other central nervous system symptoms, 3) impairment of pain control and/or opioid withdrawal, and 4) other symptoms. The most common mechanisms eliciting drug-drug interactions were alteration of opioid metabolism by inhibiting the activity of cytochrome P450 3A4 and pharmacodynamic interactions due to the combined effect on opioid, dopaminergic, cholinergic, and serotonergic activity in the central nervous system.

Conclusion: Evidence for drug-drug interactions associated with opioids used for pain treatment in cancer patients is very limited. Still, the cases identified in this systematic review give some important suggestions for clinical practice. Physicians prescribing opioids should recognize the risk of drug-drug interactions and if possible avoid polypharmacy.

Keywords: opioids, pain, cancer patients, drug-drug interactions

\section{Introduction}

Opioid analgesics are the most frequently used drugs to treat pain in patients with cancer. ${ }^{1}$ In some patients, however, opioids cause adverse effects. ${ }^{2}$ The most frequent adverse effects in cancer patients treated for pain with opioids are sedation, nausea/ vomiting, and constipation, but other infrequent adverse effects, such as myoclonus, hallucination, and respiratory depression, are also feared. ${ }^{1-3}$ Adverse drug reactions from opioids are most often caused by the opioid itself, but can also be a result of the combination of the opioid and another drug, a drug-drug interaction (DDI). ${ }^{4}$ The risk of DDIs is high in cancer patients because of the large number of concomitant drugs. ${ }^{5}$

DDIs can be categorized as pharmacokinetic, that is, one drug influences the pharmacokinetic properties - absorption, distribution, metabolism, or excretion - of another
Correspondence: Aleksandra KotlinskaLemieszek

Osiedle Rusa 55, 6I-245 Poznan, Poland

$\mathrm{Tel}+48608079698$

Fax +48 6I 8738303

Email alemieszek@ump.edu.pl 
drug. DDIs can also be pharmacodynamic, when the effects of two drugs either potentiate or antagonize each other. ${ }^{6}$

DDIs are reported to lead to serious adverse drug reactions in patients treated with opioids for pain. ${ }^{7,8}$ Still, no advice concerning the combination of opioids and other drugs is given in the current guidelines. ${ }^{2}$ Some studies have assessed the number of potentially harmful drug combinations in cancer pain patients, but do not report the number of clinically observed adverse drug reactions actually resulting from such combinations. ${ }^{5,9}$ Thus, the real risk of clinically important DDIs related to opioid therapy in cancer patients is not established.

The lack of advice on drug combinations in current guidelines may be a result of this limited clinical information. Therefore, a systematic review of the literature is indicated to identify studies that report clinically relevant DDIs associated with opioid analgesics used for the treatment of pain in patients with cancer.

\section{Methods}

\section{Search strategy}

Systematic searches were performed in Embase and MEDLINE through OvidSP and in the Cochrane Central Register of Controlled Trials, from set up of the databases (Embase from 1980) through January 2014. The last day searched was March 14, 2014. The full search string for Embase is presented in Table 1. Titles and abstracts of the retrieved citations were reviewed independently by two of the researchers (DFH, AKL), and potentially relevant papers were read in full text (DFH, AKL). In cases of doubt or disagreement, papers were reassessed by all three investigators (DFH, AKL, PK).

Additionally, reference lists of all the papers read in full text were hand-searched for relevant papers.

\section{Inclusion criteria}

- Publications reporting clinically significant DDIs involving WHO step II or step III opioids, as assessed by the authors.

- The DDI observed in one or more adult patients with a diagnosis of malignant disease and treated with an opioid for pain.
- Any type of publication: randomized controlled trial, other controlled study, observational study, case report, case series, or letter to the Editor, except for publications available only in abstract form.

- Publications in English language.

\section{Exclusion criteria}

- Experimental studies.

- Nonhuman studies.

- Only pharmacokinetic investigations (no clinical outcome).

- Studies in noncancer patients.

- Opioids used for indications other than pain or perioperatively.

- Duplicate publications.

\section{Content analysis}

The identified publications were grouped according to clinical presentation and probable underlying mechanism of the DDI. The DDIs and underlying mechanisms were presented as assessed and interpreted by the authors in each publication.

\section{Results}

\section{Systematic review of the literature}

After removal of duplicates, 901 papers were retrieved (Figure 1). A total of 112 of these papers were considered potentially eligible for inclusion. After reading the full-text papers, 17 publications were included in the final analysis. In addition, 15 relevant papers were identified through hand-searching the reference lists of the articles read in full text, adding up to a total number of 32 included publications (Table 2). ${ }^{10-41}$ Additionally, two papers that commented on two of the included publications were identified, ${ }^{42,43}$ but not included as cases in the review.

No randomized controlled trials or other controlled studies were found. All of the included publications were case reports or case series, reporting on 2-19 patients. Nine of the papers were published in the period 1983-2000, and 23 in the period 2001-January 2014 (Table 2). In some case series, DDIs in both cancer patients and patients with

Table I Search strategy

Search strategy in Embase for drug-drug interactions (DDIs) involving opioid analgesics used for pain treatment in cancer patients (\#1 or \#2 or \#3)

\#I (exp opiate agonist/it or exp narcotic analgesic agent/it or exp narcotic agent/it or exp morphine derivative/it) and exp neoplasm/ \#2 (exp opiate agonist/or exp narcotic analgesic agent/or exp narcotic agent/or exp morphine derivative/) and exp neoplasm/and (drug interaction/or drug antagonism/or drug competition/or drug inhibition/or drug potentiation/) and (exp pain/or analgesia/or analgesic activity/or pain relief/) \#3 (exp opiate agonist/or exp narcotic analgesic agent/or exp narcotic agent/or exp morphine derivative/) and exp neoplasm/and polypharmacy/ 


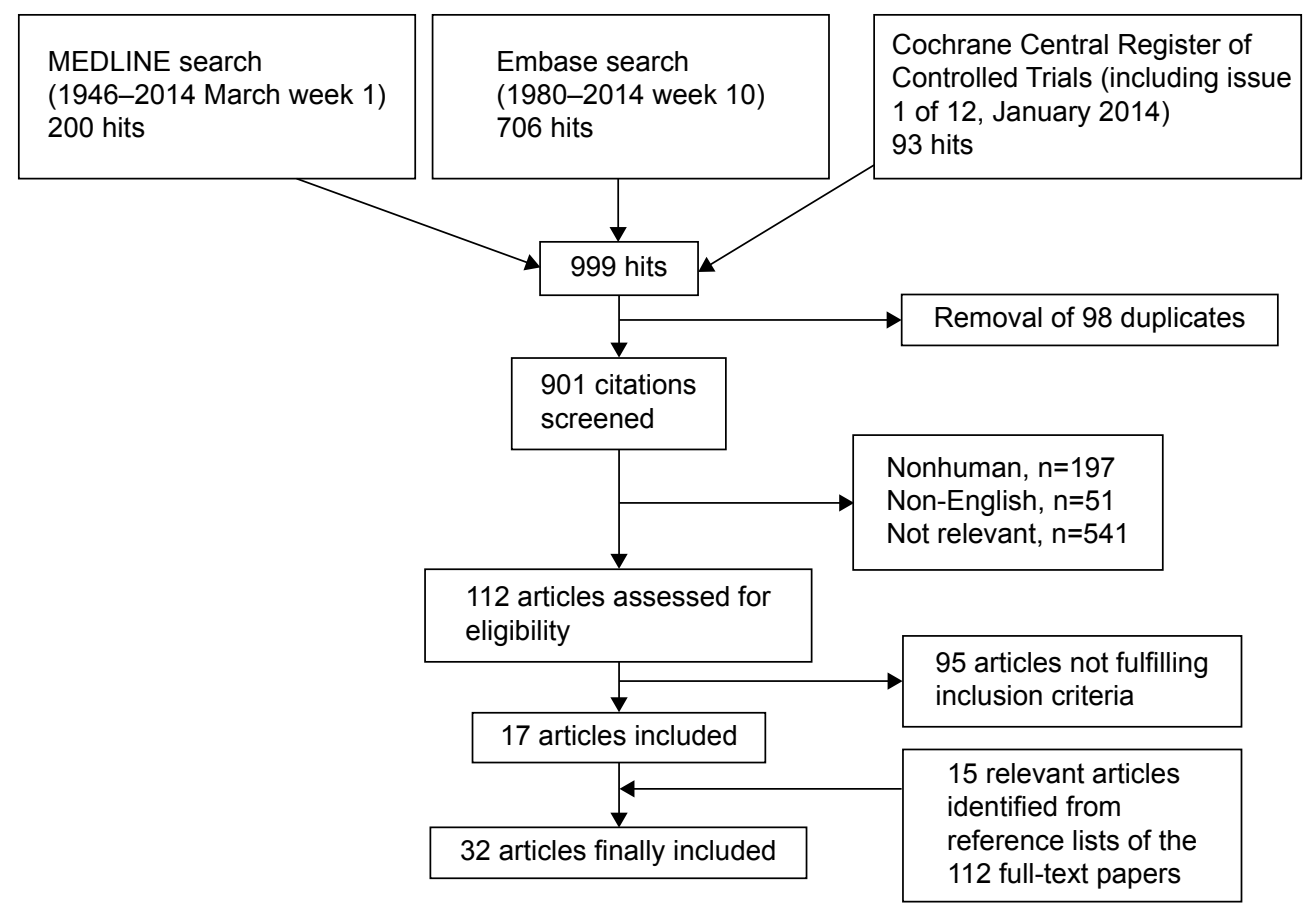

Figure I PRISMA flow chart showing the selection of papers.

nonmalignant diseases were reported. ${ }^{11,12,18,41}$ From these case series, only cases of DDIs due to opioids in patients with a diagnosis of malignant disease treated for pain were included in the review.

\section{Opioids involved in DDls}

The majority of included publications report DDIs related to opioids that are in common clinical use (Table 2):

- morphine, administered by various routes; oral, subcutaneous, intravenous, epidural, and intrathecal (nine publications), ${ }^{14-22}$

- fentanyl, transdermal, and intravenous (nine publications, ${ }^{27-35}$ of which seven described DDIs associated with transdermal preparations),

- oral methadone (six publications), ${ }^{16,37-41}$

- oral oxycodone (three publications), ${ }^{24-26}$

- tramadol combined with pethidine, ${ }^{10}$ tapentadol, ${ }^{13}$ hydromorphone, ${ }^{23}$ and buprenorphine ${ }^{36}$ was reported in one paper each.

Four publications report DDIs associated with opioids of minor current clinical relevance: propoxyphene, dextropropoxyphene, and nalbuphine. ${ }^{11,12,15,16}$

\section{Clinical presentation of DDIs}

Eleven papers reported DDIs resulting in sedation and respiratory depression. ${ }^{18,19,22,24,30,32,36-40}$ Fifteen papers reported DDIs causing various other central nervous system (CNS) symptoms, including delirium, ${ }^{10,20,23-25,29,31,34-36}$ serotonin syndrome, ${ }^{25,26,35}$ myoclonus, ${ }^{14,29,35}$ hyperalgesia, ${ }^{14}$ extrapyramidal symptoms, ${ }^{21}$ catatonia, ${ }^{10}$ neuroleptic malignant syndrome, ${ }^{34}$ or carbamazepine toxicity. ${ }^{11,12}$ Seven papers reported DDIs causing impairment of pain control and/or opioid withdrawal. ${ }^{15-17,24,27,28,33}$ Finally, in three publications, other symptoms believed to be associated with opioid-related DDIs were reported: hypertension, ${ }^{13}$ hypotension, ${ }^{24}$ vomiting, ${ }^{24}$ sweating, ${ }^{24}$ ventricular tachycardia/torsades de pointes. ${ }^{41}$

\section{Mechanisms underlying DDIs of opioids used for pain treatment in cancer patients}

The mechanisms underlying DDIs involving opioid analgesics used for pain treatment in patients with cancer in the publications included in this review are presented in Table 3.

\section{Quality of evidence}

The included studies have several limitations. Only case reports and case series were identified (Table 2). Most of the reports included in this review provide poor level of evidence. Some may also not represent true DDIs, but other opioid-related complications. However, we decided to include the reports as they were clinically evaluated and presented by the authors and published by the respective journals. 


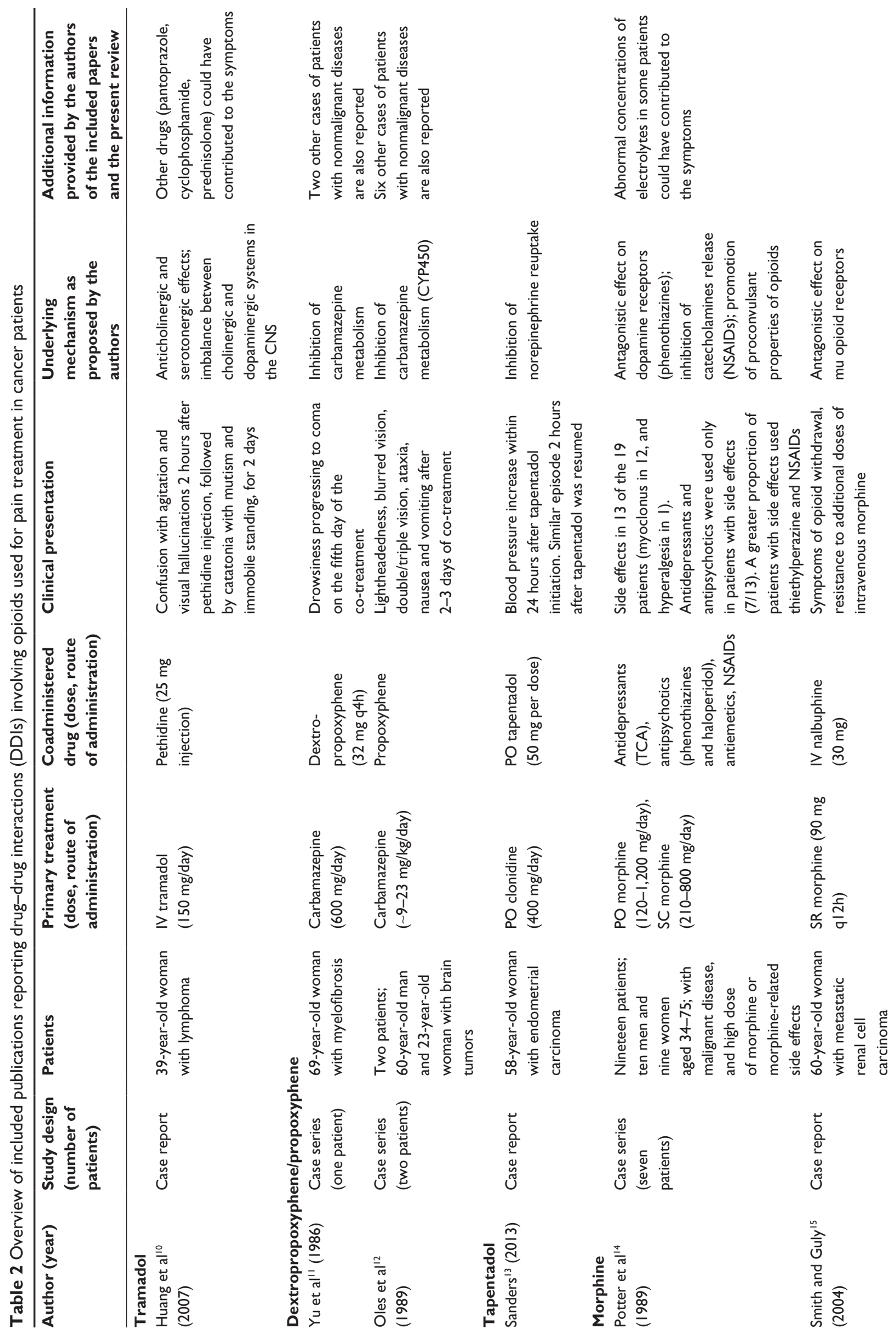



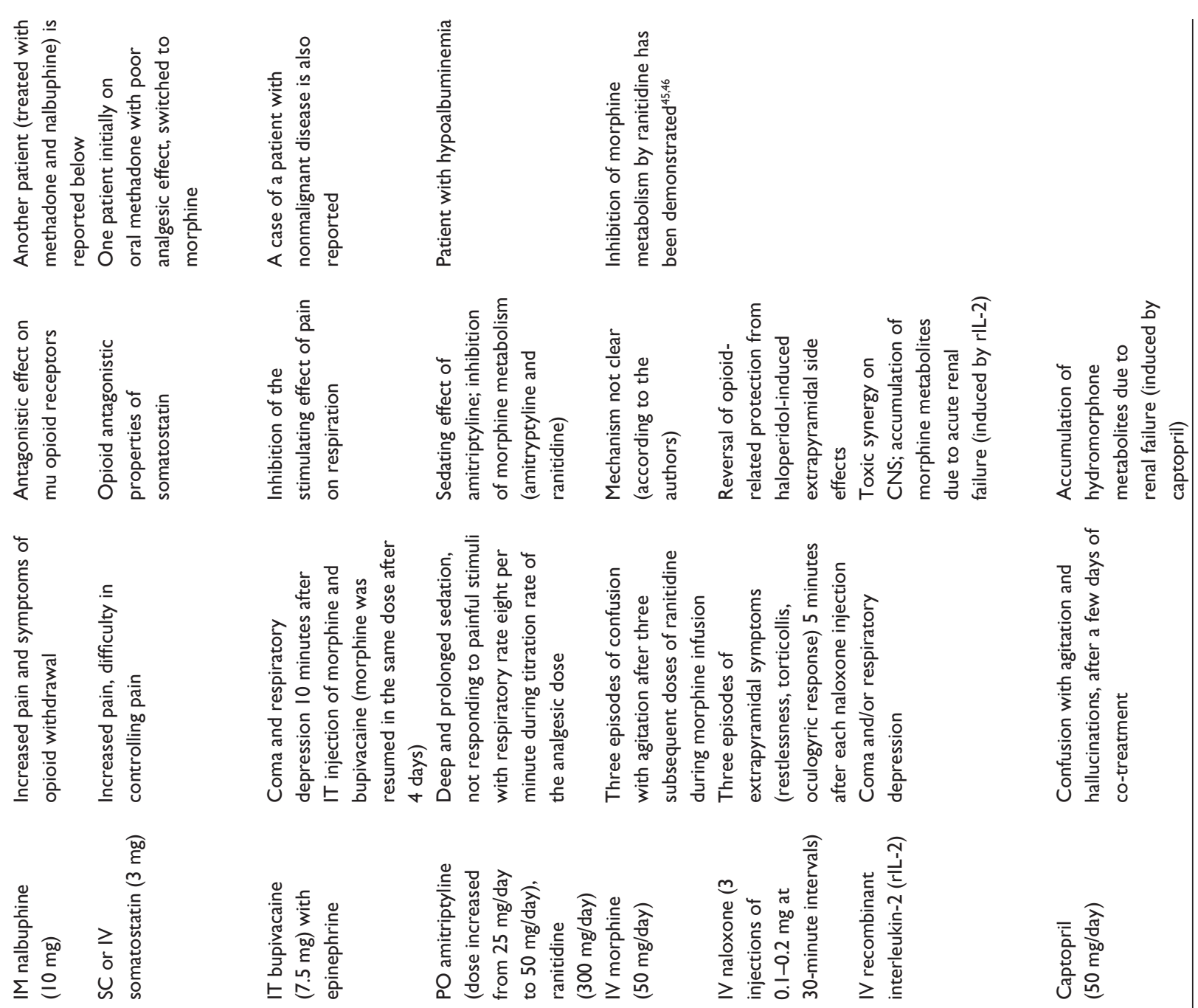

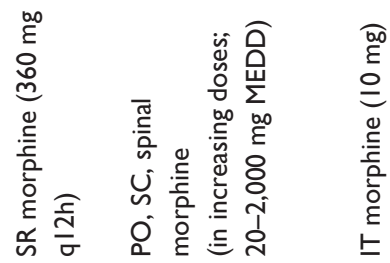
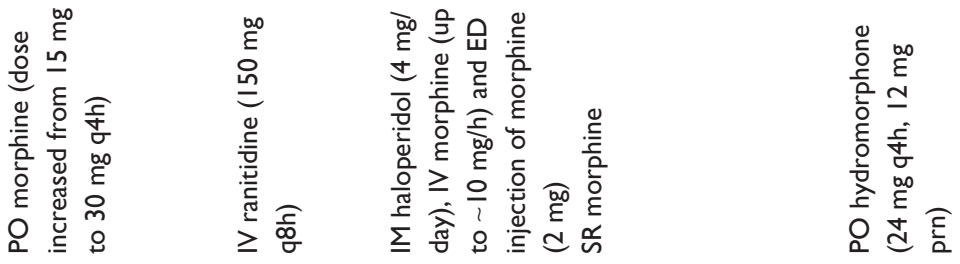

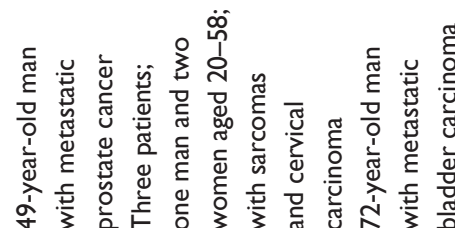
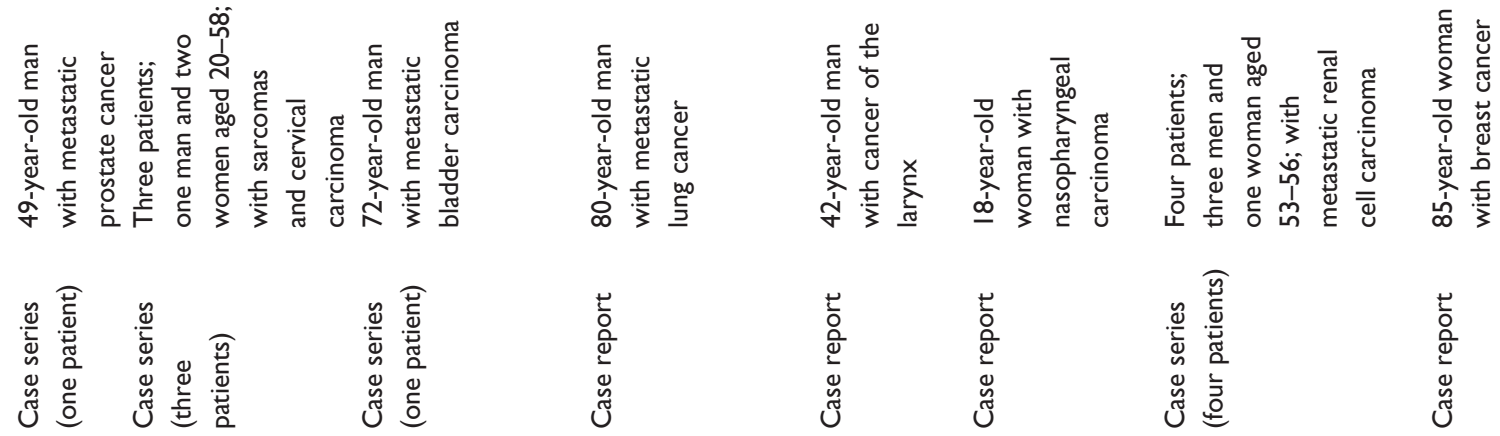

$\frac{1}{0}$
0
0
0
0
0
0

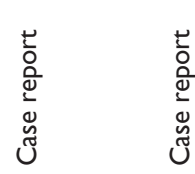

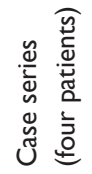
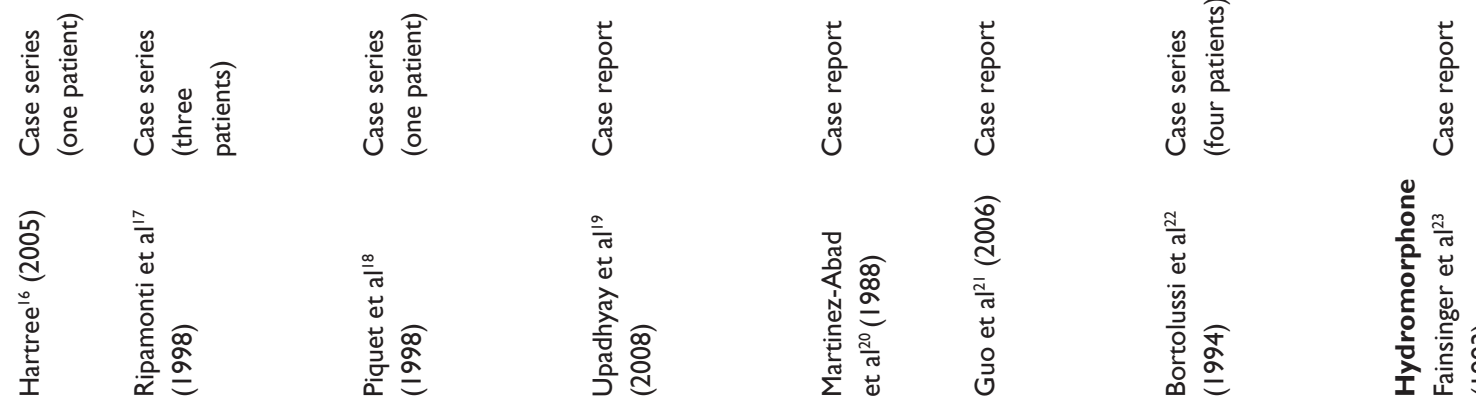

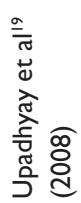
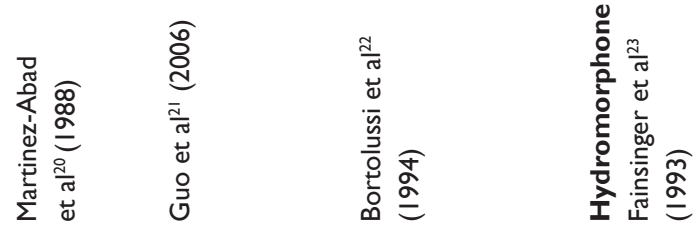


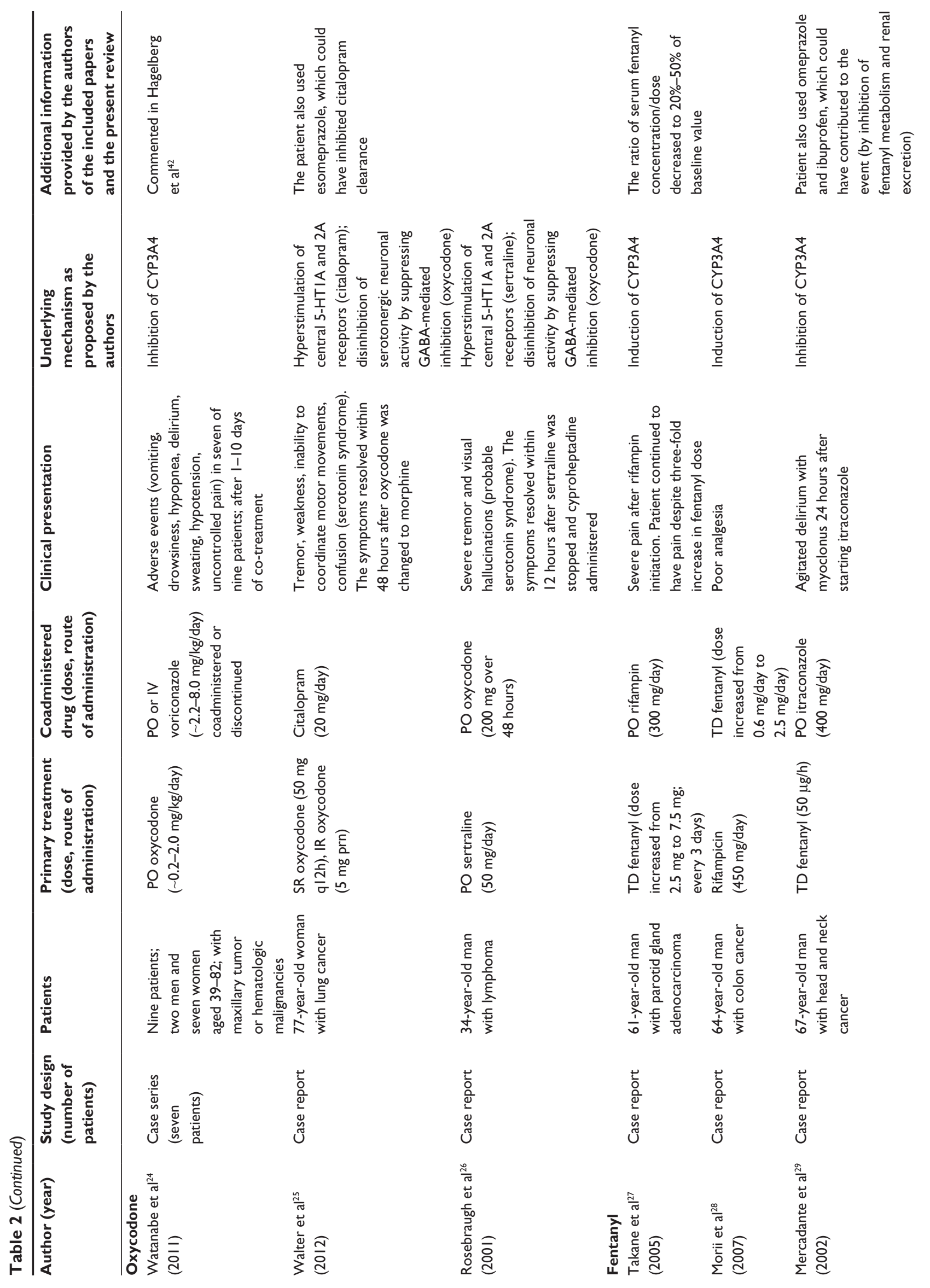



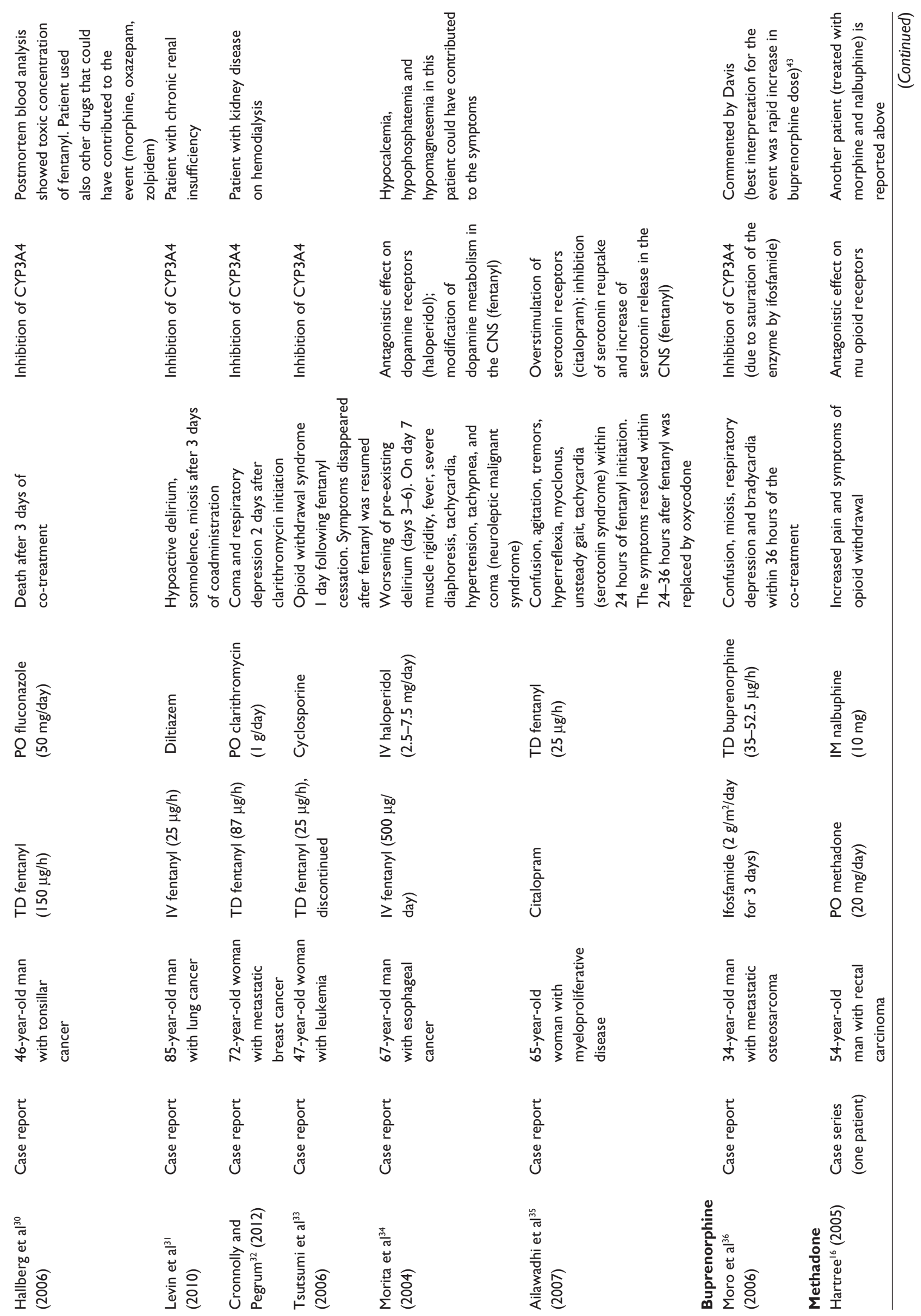

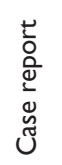

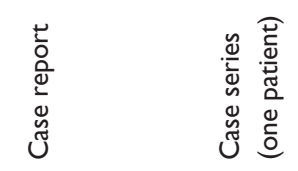




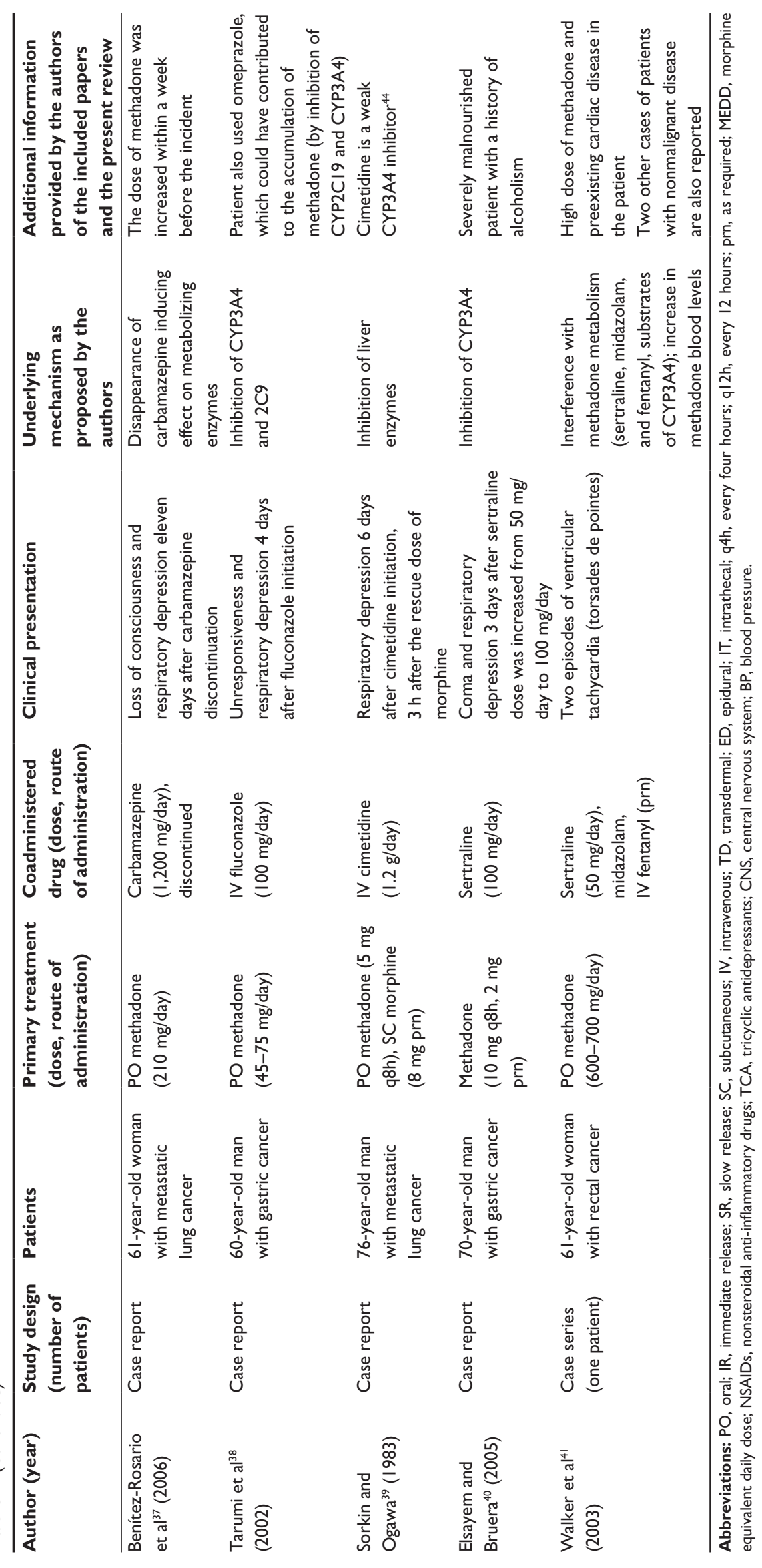


Table 3 Mechanisms underlying DDIs involving opioid analgesics used for pain treatment in patients with cancer

Mechanisms underlying DDIs of opioid analgesics

Pharmacokinetic DDIs

I) Inhibition or induction of opioid metabolism through CYP450 or other metabolizing enzymes ${ }^{19,20,24,27-33,36-41}$

2) Decreased renal elimination of an opioid 22,23

3) Inhibition of the metabolism of other drugs exerted by an opioid ${ }^{11,12}$

Pharmacodynamic DDIs

I) Potentiation of analgesic efficacy and toxicity through opioid and nonopioid mechanisms ${ }^{18,19}$

2) Inhibition or reversal of the effect of an opioid by antagonism at opioid receptors, or by other mechanisms ${ }^{15-17}$

3) Modification of cholinergic, adrenergic, dopaminergic, and serotoninergic activity in the CNS $10,13,14,25,26,34,35$

Others (including DDIs with unknown mechanism) ${ }^{21}$

Abbreviations: CNS, central nervous system; DDI, drug-drug interactions.

\section{Discussion}

Evidence for DDIs involving opioids used for pain treatment in cancer patients is very limited. This systematic review of publications on clinically significant DDIs involving opioid analgesics used for pain treatment in patients with cancer identified only case reports and case series (Table 2). ${ }^{10-41}$ As no systematic studies were identified, it was not possible to do any statistical analysis.

The three major categories of DDIs identified in the review were increased opioid effects causing sedation and respiratory depression, other CNS toxicities, and decreased opioid effects causing more pain and/or acute withdrawal symptoms. The lack of controlled studies precludes specific conclusions on the risk of DDIs associated with opioids. Still, based upon the reported cases, it can be concluded that physicians treating patients for cancer pain should be aware of and closely monitor patients for DDIs.

The DDIs with increased opioid efficacy, resulting in sedation and respiratory depression, were caused by decreased opioid metabolism, ${ }^{19,24,30,32,36-40}$ impaired renal excretion, ${ }^{22}$ or an additional therapy that also relieves pain and possesses sedative and respiratory depressant effect (eg, amitriptyline or intrathecal bupivacaine added to morphine) $)^{18,19}$ (Tables 2 and 3). Most examples identified in the review refer to opioids metabolized by cytochrome P450 (CYP450), and cytochrome P450 izoenzyme CYP3A4 (CYP3A4) in particular, such as fentanyl, methadone, oxycodone, or buprenorphine, either by concomitant use of CYP3A4 substrates and inhibitors (voriconazole, fluconazole, clarithromycin, cimetidine, and sertraline) or by discontinuation of a CYP3A4 inducer (carbamazepine) (Tables 2 and 4). ${ }^{24,30,32,36-40,44}$ Morphine pharmacokinetics were reported to be affected by a DDI leading to sedation and respiratory depression only in two case reports. ${ }^{19,22}$ In one of these publications, morphine was coadministered with amitriptyline and ranitidine,,${ }^{19}$ two drugs which can affect morphine glucuronidation ${ }^{45,46}$ (Table 2). Morphine may also indirectly be affected by renal failure caused by another drug. ${ }^{22}$ Additionally, other drugs with sedative effects can cause pharmacodynamic DDIs with an opioid. A typical observation in clinical practice is the combination of an opioid and a benzodiazepine, both contributing to sedation.

CNS symptoms (other than sedation and respiratory depression) associated with opioids included hyperactive or hypoactive delirium with or without hallucinations, serotonin toxicity, myoclonus, hyperalgesia, extrapyramidal symptoms, catatonia, and neuroleptic malignant syndrome (Table 2). CNS symptoms were related both to decreased clearance of an opioid due to decreased metabolism ${ }^{20,24,29,31,36}$ or impaired renal elimination ${ }^{23}$ and to a variety of interactions influencing several biological systems in the CNS ${ }^{10,14,21,25,26,34,35}$ (Table 3). Additionally, two reports presented cases of carbamazepine neurotoxicity related to inhibition of its metabolism by propoxyphene and dextropropoxyphene, opioids with an inhibitory effect on cytochrome P450 enzymes (Table 2). ${ }^{11,12,47}$

DDIs involving opioids can cause acute exacerbations of pain, or withdrawal symptoms (Table 2). In the identified cases, these symptoms resulted from the addition of an opioid with a mixed agonist-antagonist effect (nalbuphine), ${ }^{15,16}$ and increased or decreased metabolism of an opioid due to the coadministration of a CYP3A4 inducer (rifampin) ${ }^{27,28}$ or inhibitor (cyclosporine) $)^{33}$ or cessation of CYP3A4 inhibition (voriconazole) ${ }^{24}$ (Table 3). Nalbuphine, which is an agonist at kappa opioid receptors and an antagonist at mu opioid receptors, ${ }^{48}$ reverses the analgesic effect of mu opioid agonists when used concomitantly. ${ }^{15,16}$ Rifampin is a potent inducer of metabolizing enzymes, including CYP3A4, and may enhance clearance and attenuate the clinical effects of opioids. ${ }^{27,28,49-53}$ The withdrawal syndrome reported after discontinuation of a low dose of transdermal fentanyl $(25 \mu \mathrm{g} / \mathrm{h})$ was attributed to increased blood concentration of fentanyl (and increased effect) due to coadministration of cyclosporine, a CYP3A4 inhibitor. ${ }^{33}$ Additionally, one case series described impaired pain control in three patients who were given somatostatin as part of their antineoplastic treatment. ${ }^{17}$ The exact mechanism for this DDI is not certain. The authors suggest opioid antagonistic effect of somatostatin, demonstrated in animal studies. ${ }^{17,54}$ 
Table 4 CYP3A4 enzyme inhibitors and inducers reported to have caused clinically significant drug-drug interactions with opioids metabolized by CYP3A4 (oxycodone, methadone, fentanyl) in papers included in the present review 24,27-33,37-39,44

\begin{tabular}{|c|c|c|c|}
\hline Drugs & $\begin{array}{l}\text { Effect on } \\
\text { CYP3A4 activity }\end{array}$ & $\begin{array}{l}\text { Resulting effects when } \\
\text { coadministered with opioid }\end{array}$ & $\begin{array}{l}\text { Resulting effects after } \\
\text { withdrawal of interacting drug }\end{array}$ \\
\hline \multicolumn{4}{|c|}{ CYP3A4 inhibitors } \\
\hline Voriconazole & Strong & & \multirow{7}{*}{$\begin{array}{l}\text { Increased opioid metabolism, } \\
\text { decreased clinical effect of opioid }\end{array}$} \\
\hline Itraconazole & Strong & & \\
\hline Fluconazole & Moderate & Decreased rate of opioid metabolism, & \\
\hline Clarithromycin & Strong & increased opioid effect, increased risk & \\
\hline Diltiazem & Moderate & of opioid toxicity & \\
\hline Cyclosporine & Weak & & \\
\hline Cimetidine & Weak & & \\
\hline \multicolumn{4}{|c|}{ CYP3A4 inducers } \\
\hline Rifampin & Strong & Increased metabolism of opioid, & \multirow{2}{*}{$\begin{array}{l}\text { Decreased rate of opioid } \\
\text { metabolism, increased risk of } \\
\text { opioid overdose }\end{array}$} \\
\hline Carbamazepine & Strong & $\begin{array}{l}\text { requirement for higher opioid doses, } \\
\text { deterioration of pain control }\end{array}$ & \\
\hline
\end{tabular}

Finally, some other important DDIs were identified (Table 2). Prolonged QT time and ventricular arrhythmias (torsades de pointes) were seen in a patient receiving a high dose of methadone, and at the same time, three drugs that were CYP3A4 substrates. The authors suggest that these coadministered drugs may have interfered with methadone metabolism and caused elevation of its level in the blood. ${ }^{41}$

Multiple complex mechanisms, often not fully understood, underlie DDIs involving opioid analgesics (Table 3). In this review, we refer to the mechanisms of DDIs as they were understood and presented by the authors. In some cases, alternative causes for the observed complications may be found.

The most frequently reported mechanism of DDIs was associated with cytochrome P450 enzyme activity. In our review, the implicated opioids were fentanyl, methadone, oxycodone, and buprenorphine..$^{24,27-33,36-41}$ Of these, orally administered oxycodone and methadone have been shown to be more susceptible to DDIs related to CYP3A4 or other CYP enzymes in studies in volunteers, ${ }^{49,50,55-58}$ while fentanyl pharmacokinetics were less affected in volunteer studies. ${ }^{51,59-62}$ Still, DDIs of fentanyl associated with CYP3A4 activity were reported in seven publications identified by this review. ${ }^{27-33}$

Buprenorphine metabolism can be increased by strong CYP3A4 inducers as demonstrated in a study with rifampin, ${ }^{52}$ while the effect of CYP3A4 inhibitors is limited due to complex metabolism (conversion to norbuprenorphine by CYP3A4 and CYP2C8, and glucuronidation) as well as renal and extrarenal elimination of the parent drug and metabolites..$^{50,63}$ As noted by Davis, the case report involving buprenorphine ${ }^{36}$ should probably be best interpreted as a result of rapid dose increase before time to maximum concentration or steady state was reached, and not a DDI. ${ }^{43}$
In our review, most drugs that precipitated serious CYP3A4-mediated DDIs (voriconazole, itraconazole, fluconazole, clarithromycin, diltiazem) are also drugs relevant for patients with advanced cancer, supporting the clinical importance of this finding. The vast majority of DDIs occur after a precipitating drug is introduced. The opposite effect of a decreased or increased opioid action may be caused if the use of a CYP3A4 inhibitor or inducer is stopped, ${ }^{24,37}$ thereby decreasing or increasing the serum concentration of the drug (Table 4). Defining a consequence of stopping a drug as an interaction, is perhaps counterintuitive, but it still represents symptoms related to a pharmacokinetic DDI. Interactions are less frequent if an opioid is introduced in a patient already using another drug. This may be related to titration of the opioid dose to obtain the desired clinical effect. Thus, a DDI may change the dose, but not the clinical outcome.

In cancer patients, the coexistence of other clinical factors can increase the risk of DDIs (Table 2). Impaired renal function is a common predisposing factor of DDIs ${ }^{31,32}$ and has added importance in cancer pain management because the incidence of renal impairment in patients with advanced cancer is high..$^{64,65}$ Also, the concomitant use of other drugs and the frequent need to change coadministered drugs and their doses add to the complexity of DDIs of opioids in these patients. ${ }^{5,9}$

The presence of DDIs seems to be underreported. This lack of formal evidence may have several explanations. First, the DDI may not be detected, or the symptoms are believed to be caused by the cancer disease and, therefore, not recognized as drug related. Second, DDIs are mostly observed by clinicians, who often do not have the time, the experience, or the interest to publish clinical observations. Third, several DDIs, even if not reported in the literature, may be considered as frequent and part of common knowledge, and therefore, not 
reported. Finally, many journals only occasionally publish case reports and, perhaps, case reports are more often published in national journals and therefore not identified by a search strategy excluding non-English papers.

\section{Conclusion}

For obvious ethical reasons, there are no randomized controlled trials or other well-designed controlled studies exploring DDIs. Recommendations must therefore be based upon cases reporting serious adverse drug reactions and basic knowledge about drug mechanisms. The cases identified in this systematic review can give some suggestions for clinical practice:

- The combined use of an opioid and another drug with CNS depressant effect (eg, amitriptyline) increases the risk of acute opioid toxicity and respiratory depression. Such drugs should be carefully titrated according to effect.

- Opioids with antagonistic effects at the mu opioid receptor (eg, nalbuphine) should not be coadministered with another opioid analgesic.

- The concomitant use of an opioid and a drug, which affects the activity of cholinergic, dopaminergic, and/or serotonergic systems in the CNS (eg, selective serotonin inhibitors), can cause CNS-related complications (eg, delirium and serotonin syndrome) and should, therefore, be monitored carefully.

- Introduction of a CYP3A4 inhibitor in a patient treated with fentanyl, oxycodone, or methadone may result in opioid overdose and increased opioid toxicity (Table 4). Caution has to be undertaken when such drugs are implemented. The use of a major CYP450 inducer may impair pain treatment (Table 4). Opposite effects should be expected when these drugs are stopped (Table 4).

- Finally, the physician should recognize the risk for DDIs of opioids, monitor the patients carefully for interactions, and if possible avoid polypharmacy.

\section{Acknowledgments}

This systematic review was performed as part of the work to update the European Association for Palliative Care Guidelines for Cancer Pain Management. We thank Ingrid Riphagen for help with electronic database searches.

\section{Disclosure}

This research received no specific grant from any funding agency in the public, commercial, or not-for-profit sectors. The authors report no other conflicts of interest in this work.

\section{References}

1. World Health Organization. Cancer Pain Relief: With a Guide to Opioid Availability. 2nd ed. Geneva: WHO; 1996.

2. Caraceni A, Hanks G, Kaasa S, et al; European Palliative Care Research Collaborative (EPCRC); European Association for Palliative Care (EAPC). Use of opioid analgesics in the treatment of cancer pain: evidence-based recommendations from the EAPC. Lancet Oncol. 2012;13(2):e58-e68.

3. Laugsand EA, Kaasa S, Klepstad P. Management of opioidinduced nausea and vomiting in cancer patients: systematic review and evidence-based recommendations. Palliat Med. 2011;25(5): 442-453.

4. Bernard SA, Bruera E. Drug interactions in palliative care. J Clin Oncol. 2000;18(8):1780-1799.

5. Kotlinska-Lemieszek A, Paulsen Ø, Kaasa S, Klepstad P. Polypharmacy in patients with advanced cancer and pain: a European cross-sectional study of 2282 patients. J Pain Symptom Manage. 2014;48(6):1145-1159.

6. Osterhoudt KC, Pening TM. Drug toxicity and poisoning. In: Brunton LL, Chabner BA, Knollmann BC, editors. Goodman and Gilman's the Pharmacological Basis of Therapeutics. 12th ed. New York: McGrawHill; 2010:73-88.

7. Butts M, Jatoi A. A systematic compilation of reports published on opioid-related problems. J Opioid Manag. 2011;7(1):35-45.

8. Dahan A, Overdyk F, Smith T, Aarts L, Niesters M. Pharmacovigilance: a review of opioid-induced respiratory depression in chronic pain patients. Pain Physician. 2013;16(2):E85-E94.

9. Gaertner J, Ruberg K, Schlesiger G, Frechen S, Voltz R. Drug interactions in palliative care - it's more than cytochrome P450. Palliat Med. 2012;26(6):813-825.

10. Huang SS, Jou SH, Chiu NY. Catatonia associated with coadministration of tramadol and meperidine. J Formos Med Assoc. 2007;106(4):323-326.

11. Yu YL, Huang CY, Chin D, Woo E, Chang CM. Interaction between carbamazepine and dextropropoxyphene. Postgrad Med J. 1986;62(725):231-233.

12. Oles KS, Mirza W, Penry JK. Catastrophic neurologic signs due to drug interaction: Tegretol and Darvon. Surg Neurol. 1989;32(2): 144-151.

13. Sanders P. Tapentadol analgesic interaction with clonidine. Pain Med. 2013;14(6):943-944.

14. Potter JM, Reid DB, Shaw RJ, Hackett P, Hickman PE. Myoclonus associated with treatment with high doses of morphine: the role of supplemental drugs. BMJ. 1989;299(6692):150-153.

15. Smith J, Guly H. Nalbuphine and slow release morphine. BMJ. 2004;328(7453):1426.

16. Hartree C. Caution with nalbuphine in patients on long-term opioids. Palliat Med. 2005;19(2):168.

17. Ripamonti C, De Conno F, Boffi R, Ascani L, Bianchi M. Can somatostatin be administered in association with morphine in advanced cancer patients with pain? Ann Oncol. 1998;9(8):921-923.

18. Piquet CY, Mallaret MP, Lemoigne AH, Barjhoux CE, Danel VC, Vincent FH. Respiratory depression following administration of intrathecal bupivacaine to an opioid-dependent patient. Ann Pharmacother. 1998;32(6):653-655.

19. Upadhyay S, Jain R, Chauhan H, Gupta D, Mishra S, Bhatnagar S. Oral morphine overdose in a cancer patient antagonized by prolonged naloxone infusion. Am J Hosp Palliat Care. 2008;25(5): 401-405.

20. Martinez-Abad M, Delgado Gomis F, Ferrer JM, Morales-Olivas FJ. Ranitidine-induced confusion with concomitant morphine. Drug Intell Clin Pharm. 1988;22(11):914-915.

21. Guo SL, Lin CJ, Huang HH, Chen LK, Sun WZ. Reversal of morphine with naloxone precipitates haloperidol-induced extrapyramidal side effects. J Pain Symptom Manage. 2006;31(5):391-392.

22. Bortolussi R, Fabiani F, Savron F, et al. Acute morphine intoxication during high-dose recombinant interleukin-2 treatment for metastatic renal cell cancer. Eur J Cancer. 1994;30A(12):1905-1907. 
23. Fainsinger R, Schoeller T, Boiskin M, Bruera E. Palliative care round: cognitive failure and coma after renal failure in a patient receiving captopril and hydromorphone. J Palliat Care. 1993;9(1):53-55.

24. Watanabe M, Homma M, Momo K, et al. Effects of voriconazole co-administration on oxycodone-induced adverse events: a case in the retrospective survey. Eur J Clin Pharmacol. 2011;67(8):859-861.

25. Walter C, Ball D, Duffy M, Mellor JD. An unusual case of serotonin syndrome with oxycodone and citalopram. Case Rep Oncol Med. 2012; 2012:261787.

26. Rosebraugh CJ, Flockhart DA, Yasuda SU, Woosley RL. Visual hallucination and tremor induced by sertraline and oxycodone in a bone marrow transplant patient. J Clin Pharmacol. 2001;41(2):224-227.

27. Takane H, Nosaka A, Wakushima H, Hosokawa K, Ieiri I. Rifampin reduces the analgesic effect of transdermal fentanyl. Ann Pharmacother. 2005;39(12):2139-2140.

28. Morii H, Chiba M, Konishi H, Endo Y, Yamaji A. Failure of pain control using transdermal fentanyl during rifampicin treatment. J Pain Symptom Manage. 2007;33(1):5-6.

29. Mercadante S, Villari P, Ferrera P. Itraconazole-fentanyl interaction in a cancer patient. J Pain Symptom Manage. 2002;24(3):284-286.

30. Hallberg P, Martén L, Wadelius M. Possible fluconazole-fentanyl interaction-a case report. Eur J Clin Pharmacol. 2006;62(6): 491-492.

31. Levin TT, Bakr MH, Nikolova T. Case report: delirium due to a diltiazem-fentanyl CYP3A4 drug interaction. Gen Hosp Psychiatry. 2010;32(6):648.e9-648.e10.

32. Cronnolly B, Pegrum H. Fentanyl-clarithromycin interaction. BMJ Case Rep [published online]. 2012. doi:10.1136/bcr.02.2012.5936. http://www.ncbi.nlm.nih.gov/pmc/articles/PMC3417012/. Accessed June 30, 2014

33. Tsutsumi Y, Kanamori H, Tanaka J, Asaka M, Imamura M, Masauzi N. Withdrawal symptoms from transdermal fentanyl (TDF) after an allogeneic peripheral blood stem cell transplant (PBSCT). Pain Med. 2006;7(2):164-165.

34. Morita T, Shishido H, Tei Y, Inoue S, Nagayama K. Neuroleptic malignant syndrome after haloperidol and fentanyl infusion in a patient with cancer with severe mineral imbalance. J Palliat Med. 2004;7(6):861-864.

35. Ailawadhi S, Sung KW, Carlson LA, Baer MR. Serotonin syndrome caused by interaction between citalopram and fentanyl. J Clin Pharm Ther. 2007;32(2):199-202.

36. Moro C, Taino R, Mandalà M, Labianca R. Buprenorphine-induced acute respiratory depression during ifosfamide-based chemotherapy. Ann Oncol. 2006;17(9):1466-1467.

37. Benítez-Rosario MA, Salinas Martín A, Gómez-Ontañón E, Feria M. Methadone-induced respiratory depression after discontinuing carbamazepine administration. J Pain Symptom Manage. 2006; 32(2):99-100

38. Tarumi Y, Pereira J, Watanabe S. Methadone and fluconazole: respiratory depression by drug interaction. J Pain Symptom Manage. 2002;23(2):148-153.

39. Sorkin EM, Ogawa GS. Cimetidine potentiation of narcotic action. Drug Intell Clin Pharm. 1983;17(1):60-61.

40. Elsayem A, Bruera E. Methadone-induced respiratory depression in a patient with a history of alcoholism. J Palliat Med. 2005; 8(5):1062-1066.

41. Walker PW, Klein D, Kasza L. High dose methadone and ventricular arrhythmias: a report of three cases. Pain. 2003;103(3):321-324.

42. Hagelberg NM, Nieminen TH, Saari TI, et al. Interaction of oxycodone and voriconazole-a case series of patients with cancer pain supports the findings of randomised controlled studies with healthy subjects. Eur J Clin Pharmacol. 2011;67(8):863-864.

43. Davis MP. Buprenorphine-ifosfamide interactions? Another reason for respiratory depression. Ann Oncol [E-letter]. 2006. Available from: http://www.annonc.oxfordjournals.org/content/17/9/1466.extract/ reply\#annonc_el_86. Accessed June 30, 2014.
44. U.S. Food and Drug Administration. Drug Development and Drug Interactions: Table of Substrates, Inhibitors and Inducers; 2014. Available from: http:/www.fda.gov/drugs/developmentapprovalprocess/ developmentresources/DrugInteractionsLabeling/ucm093664.htm. Accessed June 30, 2014.

45. McQuay HJ, Carroll D, Faura CC, Gavaghan DJ, Hand CW, Moore RA. Oral morphine in cancer pain: influences on morphine and metabolite concentration. Clin Phaermacol Ther. 1990;48(3):236-244.

46. Aasmundstad TA, Størset P. Influence of ranitidine on the morphine-3-glucuronide to morphine-6-glucuronide ratio after oral administration of morphine in humans. Hum Exp Toxicol. 1998;17(6): 347-352.

47. U.S. Food and Drug Administration. Professional Drug Information; 2014. Available from: http://www.drugs.com/pro/darvon-n.html. Accessed June 30, 2014.

48. U.S. Food and Drug Administration. Professional Drug Information; 2014. Available from: http://www.drugs.com/pro/nalbuphine.html. Accessed June 30, 2014.

49. Nieminen TH, Hagelberg NM, Saari TI, et al. Rifampin greatly reduces the plasma concentrations of intravenous and oral oxycodone. Anesthesiology. 2009;110(6):1371-1378.

50. McCance-Katz EF, Sullivan LE, Nallani S. Drug interactions of clinical importance among the opioids, methadone and buprenorphine, and other frequently prescribed medications: a review. Am J Addict. 2010;19(1):4-16.

51. Kharasch ED, Whittington D, Hoffer C. Influence of hepatic and intestinal cytochrome P4503A activity on the acute disposition and effects of oral transmucosal fentanyl citrate. Anesthesiology. 2004;101(3):729-737.

52. McCance-Katz EF, Moody DE, Prathikanti S, Friedland G, Rainey PM. Rifampin, but not rifabutin, may produce opiate withdrawal in buprenorphine-maintained patients. Drug Alcohol Depend. 2011;118(2-3):326-334.

53. Fromm MF, Eckhardt K, Li S, et al. Loss of analgesic effect of morphine due to coadministration of rifampin. Pain. 1997;72(1-2):261-267.

54. Terenius L. Somatostatin and ACTH are peptides with partial antagonist-like selectivity for opiate receptors. Eur J Pharmacol. 1976;38(1):211-213.

55. Hagelberg NM, Nieminen TH, Saari TI, et al. Voriconazole drastically increases exposure to oral oxycodone. Eur J Clin Pharmacol. 2009;65(3):263-271.

56. Saari TI, Grönlund J, Hagelberg NM, et al. Effects of itraconazole on the pharmacokinetics and pharmacodynamics of intravenously and orally administered oxycodone. Eur J Clin Pharmacol. 2010; 66(4):387-397.

57. Kharasch ED, Walker A, Whittington D, Hoffer C, Bedynek PS. Methadone metabolism and clearance are induced by nelfinavir despite inhibition of cytochrome P4503A (CYP3A) activity. Drug Alcohol Depend. 2009;101(3):158-168.

58. Kharasch ED, Stubbert K. Role of cytochrome P4502B6 in methadone metabolism and clearance. J Clin Pharmacol. 2013;53(3): 305-313.

59. Ibrahim AE, Feldman J, Karim A, Kharasch ED. Simultaneous assessment of drug interactions with low- and high-extraction opioids: application to parecoxib effects on the pharmacokinetics and pharmacodynamics of fentanyl and alfentanil. Anesthesiology. 2003;98(4):853-861.

60. Palkoma VJ, Neuvonen PJ, Olkkola KT. The CYP 3 A4 inhibitor itraconazole has no effect on the pharmacokinetics of i.v. fentanyl. $\mathrm{Br} J$ Anaesth. 1998;81(4):598-600.

61. Saari TI, Laine K, Neuvonen M, Neuvonen PJ, Olkkola KT. Effect of voriconazole and fluconazole on the pharmacokinetics of intravenous fentanyl. Eur J Clin Pharmacol. 2008;64(1):25-30.

62. Olkkola KT, Palkama VJ, Neuvonen PJ. Ritonavir's role in reducing fentanyl clearence and prolonging its half-life. Anesthesiology. 1999;91(3):681-685. 
63. Kapil RP, Cipriano A, Michels GH, et al. Effect of ketoconazole on the pharmacokinetic profile of buprenorphine following administration of a once weekly buprenorphine transdermal system. Clin Drug Investig. 2012;32(9):583-592.

64. Janus N, Launay-Vacher V, Byloos E, et al. Cancer and renal insufficiency results of the BIRMA study. Br J Cancer. 2010;103(12):1815-1821.
65. Deskur-Smielecka E, Kotlinska-Lemieszek A, Niemir ZI, Wieczorowska-Tobis K. Prevalence of renal impairment in palliative care inpatients: a retrospective analysis. J Palliat Med. 2015;18(7): 613-617.

\section{Publish your work in this journal}

Drug Design, Development and Therapy is an international, peerreviewed open-access journal that spans the spectrum of drug design and development through to clinical applications. Clinical outcomes, patient safety, and programs for the development and effective, safe, and sustained use of medicines are a feature of the journal, which has also been accepted for indexing on PubMed Central. The manuscript management system is completely online and includes a very quick and fair peer-review system, which is all easy to use. Visit http://www.dovepress.com/testimonials.php to read real quotes from published authors.

Submit your manuscript here: http://www.dovepress.com/drug-design-development-and-therapy-journal 